\title{
Leishmanicidal compounds of Nectria pseudotrichia, an endophytic fungus isolated from the plant Caesalpinia echinata (Brazilwood)
}

\author{
Betania Barros Cota ${ }^{1 /+}$, Luiza Guimarães Tunes², Daniela Nabak Bueno Maia', Jonas Pereira Ramos ${ }^{3}$, \\ Djalma Menezes de Oliveira ${ }^{4}$, Markus Kohlhoff', Tânia Maria de Almeida Alves ${ }^{1}$, \\ Elaine Maria Souza-Fagundes ${ }^{3}$, Fernanda Fraga Campos ${ }^{5}$, Carlos Leomar Zani'
}

\author{
1Fundação Oswaldo Cruz-Fiocruz, Instituto René Rachou, Laboratório de Química de Produtos Naturais Bioativos, Belo Horizonte, MG, Brasil \\ ${ }^{2}$ Fundação Oswaldo Cruz-Fiocruz, Instituto René Rachou, Laboratório de Genômica Funcional e Proteômica \\ de Leishmania spp. e Trypanosoma cruzi, Belo Horizonte, MG, Brasil \\ ${ }^{3}$ Universidade Federal de Minas Gerais, Departamento de Fisiologia e Biofísica, Belo Horizonte, MG, Brasil \\ ${ }^{4}$ Universidade Estadual do Sudoeste da Bahia, Departamento de Química, Jequié, BA, Brasil \\ ${ }^{5}$ Universidade Federal dos Vales do Jequitinhonha e Mucuri, Departamento de Ciências Biológicas e da Saúde, Diamantina, MG, Brasil
}

BACKGROUND In a screen of extracts from plants and fungi to detect antileishmanial activity, we found that the ethyl acetate extract of the fungus Nectria pseudotrichia, isolated from the tree Caesalpinia echinata (Brazilwood), is a promising source of bioactive compounds.

OBJECTIVES The aims of this study were to isolate and determine the chemical structures of the compounds responsible for the antileishmanial activity of the organic extract from $N$. pseudotrichia.

METHODS Compounds were isolated by chromatographic fractionation using semi-preparative high-performance liquid chromatography, and their chemical structures were determined by analytical and spectral data and by comparison with published data. The antileishmanial activity of the isolated compounds was evaluated in intracellular amastigote forms of Leishmania (Viannia) braziliensis expressing firefly luciferase as reporter gene, and cytotoxicity was determined in Vero and THP-1 mammalian cell lines by MTT assay.

FINDINGS Fractionation of the extract yielded seven compounds: 10-acetyl trichoderonic acid A (1), 6'-acetoxy-piliformic acid (2), 5',6'-dehydropiliformic acid (3), piliformic acid (4), hydroheptelidic acid (5), xylaric acid D (6), and cytochalasin D (7). Compounds 1, 2 and 3 are reported here for the first time. Compounds 1, 2, and 5 were more active, with $\mathrm{IC}_{50}$ values of 21.4, 28.3, and $24.8 \mu \mathrm{M}$, respectively, and showed low toxicity to Vero and THP-1 cells.

MAIN CONCLUSIONS $N$. pseudotrichia produces secondary metabolites that are more toxic to intracellular amastigote forms of L. (V.) braziliensis than to mammalian cells.

Key words: fungal metabolites - natural products - Leishmania braziliensis - antileishmanial - neglected disease

Leishmaniasis is a group of human diseases caused by protozoan species of the genus Leishmania, which are prevalent in tropical and subtropical areas of the world (WHO 2010). Brazil is among the ten countries affected by $90 \%$ of the cases worldwide of both cutaneous and visceral leishmaniasis (WHO 2010).

Leishmania (Viannia) braziliensis is the main etiological agent of American tegumentary leishmaniasis (ATL) and has highest incidence in Brazil. This group of infectious diseases has different clinical forms that are associated with the molecular diversity of the parasite and host immune response (Pereira et al. 2017). The control of ATL has been based on chemotherapy with pentavalent antimonials for more than 70 years. Meglumine

\footnotetext{
doi: 10.1590/0074-02760170217

Financial support: CNPq, FAPEMIG, PDTIS-FIOCRUZ (RPT-10A and RPT13-A).

+ Corresponding author: betania@minas.fiocruz.br

Received 1 June 2017

Accepted 22 August 2017
}

antimoniate (Glucantime $\left.{ }^{\circledR}\right)$ is a first-line drug, but use of this therapeutic is limited by its high cost and toxicity. Although there is little evidence of treatment failure for Glucantime ${ }^{\circledR}$ in Brazil (Nassif et al. 2016), the use of pentavalent antimonials are contraindicated in pregnancy and in patients with heart or renal disease, and they require daily parenteral administration. Thus, there is a need for the discovery of new leads or scaffolds that can be used to develop less toxic drugs and alternative oral treatments (Prates et al. 2017).

As part of our program to investigate endophytic fungi as sources of natural products with biological activities, particularly against neglected infectious diseases, we found that the ethyl acetate (EtOAc) extract from the culture of Nectria pseudotrichia (Nectriaceae), an ascomycete isolated from the tree Caesalpinia echinata (Fabaceae), was active against amastigote-like forms of Leishmania (Leishmania) amazonensis (Campos et al. 2015), showing an $\mathrm{IC}_{50}$ value of $4.6 \mu \mathrm{g} / \mathrm{mL}$. Although the genus Nectria is known to produce a wide range of secondary metabolites (Parisot et al. 1983, Irvine et al. 2008, Wang et al. 2012), there are no reports on the isolation of natural products from $N$. pseudotrichia. These facts prompted us to pursue the isolation and identifi- 
cation of the compound(s) responsible for the observed antileishmanial activity, and contribute to knowledge of the chemistry of this fungus. In addition, we report herein three novel compounds (1-3) for the first time.

\section{MATERIALS AND METHODS}

Fungal material - The stems of C. echinata Lam. (Fabaceae) were collected by JO Rego, IR Andrade, ACO Nogueira, and MGC Fernandes at the Zoo-Botanical Foundation, Belo Horizonte (FZB-BH), state of Minas Gerais, Brazil. A voucher specimen was deposited at Fundação Zoo-Botânica Herbarium under the code BHZB-6458. A sample of the isolated fungus was deposited at the Microorganisms and Cells Collection of the Federal University of Minas Gerais, Brazil. It was identified as N. pseudotrichia (Schwein.) Berk \& MA Curtis (Nectriaceae) based on the internal transcribed spacer (ITS1-5.8S-ITS2) rDNA analysis using universal fungal primers, and the sequences were deposited in GenBank with the accession number KF611677 (Campos et al. 2015).

Fermentation and extraction - Two-mm-diameter plugs of endophytic fungus culture were inoculated into the centres of 90 Petri dishes (90 mm diameter) containing $20 \mathrm{~mL}$ malt extract agar medium (malt extract 1\% w/v, glucose $1 \% \mathrm{w} / \mathrm{v}$, peptone $0.1 \% \mathrm{w} / \mathrm{v}$ and agar $1 \% \mathrm{w} / \mathrm{v}$ in 1 $\mathrm{L}$ purified water) and incubated at $25 \pm 2{ }^{\circ} \mathrm{C}$ for 14 days. The cultures were extracted three times by maceration with EtOAc for $48 \mathrm{~h}$ at room temperature. After passing through a filter paper, the solvents were evaporated at $45^{\circ} \mathrm{C}$ under reduced pressure in a rotary-evaporator. Residual solvent in the extracts was eliminated in a vacuum centrifuge at $40^{\circ} \mathrm{C}$ to yield $2.83 \mathrm{~g}$ of crude extract.

Chromatographic fractionation - Analytical high-performance liquid chromatography (HPLC) was performed on a Shim-pack ${ }^{\circledR}$ C18 column $(5 \mu \mathrm{M}, 4.6 \mathrm{~mm}$ i.d. $\mathrm{x} 250$ $\mathrm{mm}$ ), using a chromatograph equipped with LC10AD pumps, a mixing valve, and an SPD M-10A VP Diode Array Detector (Shimadzu, Kyoto, Japan). Semi preparative purifications were performed on a Shim-pack ${ }^{\circledR}$ C18 (5 $\mu \mathrm{M}, 20 \mathrm{~mm}$ i.d. $\mathrm{x} 250 \mathrm{~mm}$ ) column using a chromatograph with two LC6AD pumps and an SPD-10A-UV detector (Shimadzu). Thin-layer chromatography (TLC) analyses were conducted on pre-coated silica gel G-60/F254 plates (0.25 mm, Merck, Darmstadt, Germany). The spots were visualized after heating the plate sprayed with a mixture of equal parts of ethanol solutions of vanillin $(1 \% \mathrm{w} / \mathrm{v})$ and sulphuric acid $(10 \% \mathrm{v} / \mathrm{v})$. Medium pressure column chromatography (MPLC) was performed over $\mathrm{C} 18$ silica gel (20-40 $\mu \mathrm{M}$ particle size) using a step gradient from 10 to $100 \% \mathrm{MeOH}$ in water and collecting 136 fractions of 50 $\mathrm{mL}$ each. Fractions were pooled into 33 groups according to the similarity of their behaviour on TLC. Thus, group 12 (105 mg) was separated on a RP-C18 column using a $60 \mathrm{~min}$ linear gradient of 10 to $60 \%$ of $\mathrm{MeOH}$ in water, stepping to $100 \% \mathrm{MeOH}$ and proceeding with this solvent for $10 \mathrm{~min}$, yielding compounds 1 (18.9 mg), $5(4.1 \mathrm{mg})$, and 6 (4.9 mg). Group 13 (300 mg) was also purified by a semi-preparative RP-C18 column, using a 60 min linear gradient from 50 to $100 \% \mathrm{MeOH}$ in water, and held at $100 \%$ for $30 \mathrm{~min}$, providing compounds $2(32.1 \mathrm{mg})$ and
3 (39.0 mg). In the same way, group 14 (149 mg), after a 60 min linear gradient from 10 to $100 \% \mathrm{MeOH}$ in water, yielded compound 7 (20.2 mg), while group 15 (130 mg) provided compound 4 (9.4 mg).

Analytical methods - Optical rotations were recorded using an Anton Paar MCP 300 polarimeter (Anton Paar, Graz, Austria). UV spectra were obtained in a SPD M-10A VP Diode Array Detector (Shimadzu). 1D and 2D NMR experiments were acquired with a Bruker Avance $400 \mathrm{MHz}$ spectrometer (Bruker Daltonics, Bremen, Germany) using TMS as an internal standard. High-resolution mass spectral data were obtained on a maXis ETD ESI-QTOF (Bruker Daltonics) coupled to a Nexera UHPLC-system (Shimadzu) using a reverse phase column (Shim-Pack XR-ODSIII, $2.2 \mu \mathrm{M}$ particle diameter, $2.1 \mathrm{x}$ $200 \mathrm{~mm}$, i.d) at $40^{\circ} \mathrm{C}$ under a flow rate of $200 \mu \mathrm{L} / \mathrm{min}$. The mobile phases were $0.1 \% \mathrm{v} / \mathrm{v}$ formic acid in (A) water and (B) ACN. A mixture of 5\% B was pumped for 0.5 min followed by a linear gradient from 5 to $100 \%$ B over $12.5 \mathrm{~min}$ and a hold at $100 \% \mathrm{~B}$ for $1 \mathrm{~min}$. The following conditions were used: end plate offset $-500 \mathrm{~V}$; capillary voltage $4500 \mathrm{~V}$; nebuliser pressure 2.0 bar; dry gas (nitrogen) flow rate $8.0 \mathrm{~L} / \mathrm{min}$; dry gas temperature $200^{\circ} \mathrm{C}$. Data-dependent precursor fragmentation was performed at collision energies of $40 \mathrm{eV}$. Ion cooler settings were optimised within a $40-1000 \mathrm{~m} / \mathrm{z}$ range using a solution of $10 \mathrm{~mm}$ sodium formate in $50 \%$ aq. 2-propanol as calibrant. Mass calibration was achieved by initial in-source infusion of $20 \mu \mathrm{L}$ calibrant solution and post-acquisition recalibration of the raw data.

Analytical and spectral data of isolated compounds - Compound 1: colourless oil. $[\alpha]_{\mathrm{D}}^{25}+51.0(c$ 1.7, $\mathrm{MeOH})$. UV: transparent above $1220 \mathrm{~nm}$. HRMS: $[\mathrm{M}+\mathrm{H}]^{+}, m / z 341.1593\left(\mathrm{C}_{17} \mathrm{H}_{24} \mathrm{O}_{7}, 0.6 \mathrm{ppm}\right) \mathrm{NMR}$ data are shown in Table I.

Compound 2: pale yellow gum. $[\alpha]_{\mathrm{D}}^{25}+30.0$ (c 1.6, $\mathrm{MeOH})$. UV: transparent above $1220 \mathrm{~nm}$. HRMS: $[\mathrm{M}+\mathrm{H}]^{+}, m / z 273.1334\left(\mathrm{C}_{13} \mathrm{H}_{20} \mathrm{O}_{6}, 0.4 \mathrm{ppm}\right)$. NMR data are shown in Table II.

Compound 3: white powder. $[\alpha]_{\mathrm{D}}^{25}+24.0$ (c 2.0, $\mathrm{MeOH})$. UV: transparent above $1220 \mathrm{~nm}$. HRMS: $[\mathrm{M}+\mathrm{H}]^{+}, m / z 213.1121\left(\mathrm{C}_{11} \mathrm{H}_{16} \mathrm{O}_{4}, 0.1 \mathrm{ppm}\right)$. NMR data are shown in Table III.

Assays with L. (V.) braziliensis - L. (V.) braziliensis (strain MHOM/BR/1994/H3227) promastigotes were maintained in minimum essential culture medium ( $\alpha$-MEM) (Gibco/Brl, Grand Island, NY, USA) supplemented with $10 \%(\mathrm{v} / \mathrm{v})$ heat inactivated foetal bovine serum (FBS, Cultilab, Campinas, SP, Brazil), $100 \mathrm{mg} / \mathrm{mL}$ kanamycin, $50 \mathrm{mg} / \mathrm{mL}$ ampicillin, $2 \mathrm{~mm}$ L-glutamine, 5 $\mathrm{mg} / \mathrm{mL}$ hemin, and $5 \mathrm{~mm}$ biopterin (Sigma-Aldrich, St. Louis, USA), at $\mathrm{pH} 7.0$ and incubated at $25^{\circ} \mathrm{C}$.

For this assay, we used L. (V.) braziliensis LUC expressing firefly luciferase as a reporter gene. The transfection was performed as previously described (Roy et al. 2000). Human monocyte-derived macrophage cell line, THP-1, was maintained in RPMI 1640 medium supplemented with $10 \%$ FBS and differentiated in the presence of $20 \mathrm{ng} / \mathrm{mL}$ phorbol myristate for $72 \mathrm{~h}$ at $37^{\circ} \mathrm{C}$. 
TABLE I

NMR Spectroscopic Data (400 MHz in $\mathrm{CD}_{3} \mathrm{OD}$ ) for compound 1

\begin{tabular}{|c|c|c|c|}
\hline C position & $\delta_{\mathrm{C}}$ (mult.) & $\delta_{\mathrm{H}}($ mult., $J \mathrm{~Hz})$ & $\mathrm{HMBC}^{*}$ \\
\hline 1 & $50.98, \mathrm{CH}$ & $2.64(\mathrm{~d}, 10.1)$ & $2,5,6,10,14$ \\
\hline 2 & $177.85, \mathrm{C}$ & & \\
\hline 3 & $57.61, \mathrm{CH}_{2}$ & $\begin{array}{l}\text { a: } 4.28(\mathrm{~d}, 12.3) \\
\mathrm{b}: 4.16(\mathrm{~d}, 12.3)\end{array}$ & $\begin{array}{l}4,5,17 \\
4,5,17\end{array}$ \\
\hline 4 & $135.30, \mathrm{C}$ & & \\
\hline 5 & $145.29, \mathrm{CH}$ & $6.68(\mathrm{~d}, 10.5)$ & $3,4,7,17$ \\
\hline 6 & $40.58, \mathrm{CH}$ & $2.86(\mathrm{ddd}, 10.5,10.5,10.1)$ & $1,2,4,5,7$ \\
\hline 7 & $45.87, \mathrm{CH}$ & 1.44 (tt like, $10.5,3.0)$ & \\
\hline 8 & $21.29, \mathrm{CH}_{2}$ & $1.80(\mathrm{~m})$ & 6,10 \\
\hline 9 & $28.75, \mathrm{CH}_{2}$ & $\begin{array}{l}\text { eq: } 2.44(\mathrm{dt} \text { br., } 14.0,4.4,4.4) \\
\text { ax: } 2.07(\mathrm{~m})\end{array}$ & 1,10 \\
\hline 10 & $86.24, \mathrm{C}$ & & \\
\hline 11 & $29.49, \mathrm{CH}$ & $1.75(\mathrm{~m})$ & \\
\hline 12 & $16.31, \mathrm{CH}_{3}$ & $0.78(\mathrm{~d}, 6.8)$ & $7,11,13$ \\
\hline 13 & $21.96, \mathrm{CH}_{3}$ & $0.98(\mathrm{~d}, 6.8)$ & $7,11,12$ \\
\hline 14 & $73.30, \mathrm{CH}_{2}$ & $\begin{array}{l}4.66(\mathrm{~d}, 11.0) \\
4.55(\mathrm{~d}, 11.0)\end{array}$ & $\begin{array}{l}1,2,10 \\
2,9,10\end{array}$ \\
\hline 15 & $172.00, \mathrm{C}$ & & \\
\hline $\begin{array}{l}16 \\
17\end{array}$ & $\begin{array}{c}21.91, \mathrm{CH}_{3} \\
170.34, \mathrm{C}\end{array}$ & $2.02,(\mathrm{~s})$ & $10,14,15$ \\
\hline
\end{tabular}

*: the numbers correspond to carbon atoms as shown in Fig. 2.

Cells were infected with $L$. ( V.) braziliensis LUC promastigotes at a parasite/macrophage ratio of 10:1 for 3 $\mathrm{h}$ in a white walled 96-well tissue culture plate. Non-internalised parasites were removed by five washes with HEPES/ NaCl buffer (20 mm HEPES, $0.15 \mathrm{M} \mathrm{NaCl}, 10$ $\mathrm{mm}$ glucose, $\mathrm{pH}$ 7.2). The infected cells were then treated with 1.5-200.0 $\mu \mathrm{g} / \mathrm{mL}$ of sample-tests and 0.006-0.8 $\mu \mathrm{M}$ of amphotericin B (positive control). After $72 \mathrm{~h}$, RPMI was aspirated and luciferase activity was assessed by adding $20 \mu \mathrm{L}$ reconstituted One-Glo ${ }^{\text {TM }}$ Luciferase Assay system solution as enzyme substrate, following the manufacturer's instructions (Promega, Madison, WI, USA). Luciferase activity was measured by luminescence detection in a SpectraMax M5 luminometer (Molecular Devices, Sunnyvale, CA, USA) using $1 \mathrm{~s}$ integration/well. Non-infected THP-1 macrophages were used as signal background while non-treated infected THP-1 macrophages were used as control for growth comparison. Antileishmanial activity was expressed as the concentration required to inhibit $50 \%$ of parasite growth, as calculated by sigmoidal regression analyses using GraphPad Prism (Version 6.0c, GraphPad Software Inc., La Jolla, CA, USA).

To assess toxicity of the compounds on the host cells, THP-1 macrophages were seeded in 96-well plates at a density of $2 \times 10^{5}$ cells per well, differentiated in the presence of $20 \mathrm{ng} / \mathrm{mL}$ phorbol myristate for $72 \mathrm{~h}$ at $37^{\circ} \mathrm{C}$, and treated with $1.5-200.0 \mu \mathrm{g} / \mathrm{mL}$ of the compounds or 1.5-200.0 $\mu \mathrm{M}$ of Amphotericin B. After $72 \mathrm{~h}$ treatment with compounds, cell death was estimated using MTT, which is metabolised by viable cells resulting in a purple product that can be quantified using a spectrophotometer (absorbance at $570 \mathrm{~nm}$ ). The results were calculated from the absorbance measurements using the percentage of cell death in relation to the untreated cell controls.

Cytotoxicity assay using Vero cells - African green monkey kidney cells (Vero) were used as model of normal cells and were provided by Erna Kroon (Federal University of Minas Gerais, Brazil). The cells were maintained in DMEM medium (Sigma-Aldrich), containing 5\% FBS (Gibco/Brl), enriched with $1 \%$ antibiotic solution $(100 \mathrm{IU} / \mathrm{mL}$ penicillin and $100 \mu \mathrm{g} / \mathrm{mL}$ streptomycin, Gibco/Brl). Vero cells were inoculated in 96 well plates at $1 \times 10^{4}$ cells/well and the plates incubated for $24 \mathrm{~h}$ at $37^{\circ} \mathrm{C}$. The samples and amphotericin B (positive control) were dissolved in DMSO (Sigma-Aldrich). The half maximal inhibitory concentration $\left(\mathrm{IC}_{50}\right)$ was determined over a range of concentrations ( 9 nonserial dilutions: 200.0 to $0.78 \mu \mathrm{M})$. All cell cultures were incubated in a $5 \% \mathrm{CO}_{2} / 95 \%$ humidified air atmosphere at $37^{\circ} \mathrm{C}$ for $72 \mathrm{~h}$. Wells with $0.5 \% \mathrm{v} / \mathrm{v}$ DMSO were used as a negative control. All medium and reagents used in the assays were endotoxin free. Cell viability was estimated by measuring the mitochondrial reduction of MTT (Monks et al. 1991). The samples were tested in triplicate in two independent experiments. The results were expressed as percentage of viability in relation to the negative control (DMSO, $0.5 \% \mathrm{v} / \mathrm{v})$, calculated as follows: percentage of cell viability $(\%)=[($ treated mean OD $/$ negative control $)$ $\mathrm{x}$ 100] and obtained from two independent experiments 
TABLE II

NMR Spectroscopic Data (400 MHz in $\mathrm{CD}_{3} \mathrm{OD}$ ) for compound 2

\begin{tabular}{|c|c|c|c|}
\hline \multirow[b]{2}{*}{ C position } & \multicolumn{3}{|c|}{ Compound 2} \\
\hline & $\delta_{\mathrm{C}}$ (mult.) & $\delta_{\mathrm{H}}($ mult., $J \mathrm{~Hz})$ & HMBC $^{*}$ \\
\hline 1 & $170.23, \mathrm{C}$ & & \\
\hline 2 & $134.65, \mathrm{C}$ & & \\
\hline 3 & 39.01, CH & $3.63(\mathrm{q}, 7.1)$ & $2,4,1^{\prime}, 7^{\prime}$ \\
\hline 4 & $177.99, \mathrm{C}$ & & \\
\hline 1 ' & $144.89, \mathrm{CH}$ & $6.82(t, 7.6)$ & $1,2,3,1^{\prime}, 2^{\prime}$ \\
\hline $2^{\prime}$ & $29.48, \mathrm{CH}_{2}$ & $\begin{array}{l}\text { a: } 2.23(\text { dddd, } 14.0,7.6,7.0,7.0) \\
\text { b: } 2.28(\text { dddd, } 14.0,7.6,7.0,7.0)\end{array}$ & $2,1^{\prime}, 3^{\prime}$ \\
\hline $3^{\prime}$ & $29.44, \mathrm{CH}_{2}$ & 1.53 (quin like, 7.1 ) & $1^{\prime}, 2^{\prime}, 4^{\prime}$ \\
\hline $4^{\prime}$ & $26.85, \mathrm{CH}_{2}$ & $1.43(\mathrm{~m})$ & 3 ' \\
\hline $5^{\prime}$ & $29.64, \mathrm{CH}_{2}$ & 1.66 (quin like, $7.2,6.6$ ) & $3^{\prime}, 4^{\prime}, 6^{\prime}$ \\
\hline $6^{\prime}$ & $65.68, \mathrm{CH}_{2}$ & $4.06(\mathrm{dd}, 6.6)$ & $4^{\prime}, 5^{\prime}, 1^{\prime \prime}$ \\
\hline $7^{\prime}$ & $16.50, \mathrm{CH}_{3}$ & $1.30(\mathrm{~d}, 7.1)$ & $2,3,4$ \\
\hline $1 "$ & $173.23, \mathrm{C}$ & & \\
\hline $2 "$ & $20.97, \mathrm{CH}_{3}$ & $2.02(\mathrm{~s})$ & $1 "$ \\
\hline
\end{tabular}

*: the numbers correspond to carbon atoms as shown in Fig. 2.

TABLE III

NMR Spectroscopic Data (400 MHz in $\mathrm{CD}_{3} \mathrm{OD}$ ) for compound 3

\begin{tabular}{|c|c|c|c|}
\hline \multirow[b]{2}{*}{ C position } & \multicolumn{3}{|c|}{ Compound 3} \\
\hline & $\delta_{\mathrm{C}}$ (mult.) & $\delta_{\mathrm{H}}($ mult., $J \mathrm{~Hz})$ & $\mathrm{HMBC}^{*}$ \\
\hline 1 & $170.06, \mathrm{C}$ & & \\
\hline 2 & $134.61, \mathrm{C}$ & & \\
\hline 3 & $38.90, \mathrm{CH}$ & $3.62(\mathrm{q}, 7.1)$ & $1,2,4,1^{\prime}, 7^{\prime}$ \\
\hline 4 & $177.87, \mathrm{C}$ & & \\
\hline $1^{\prime}$ & $144.84, \mathrm{CH}$ & $6.84(\mathrm{t}, 7.6)$ & $1,2,3,1^{\prime}, 2^{\prime}$ \\
\hline $2^{\prime}$ & $28.97, \mathrm{CH}_{2}$ & $\begin{array}{l}\text { a: } 2.22 \text { (dddd, } 14.0,7.6,7.0,7.0) \\
\text { b: } 2.27 \text { (dddd, 14.0, 7.6, 7.0, 7.0) }\end{array}$ & $2,1^{\prime}, 4^{\prime}$ \\
\hline $3^{\prime}$ & $29.18, \mathrm{CH}_{2}$ & 1.59 (quin like, 7.6, 7.3) & $1^{\prime}, 4^{\prime}, 5^{\prime}$ \\
\hline 4 ' & $34.51, \mathrm{CH}_{2}$ & $2.11(\mathrm{qt}, 7.2,1.5)$ & $3^{\prime}, 5^{\prime}, 6^{\prime}$ \\
\hline 5 & $139.52, \mathrm{CH}$ & $5.83(\mathrm{ddt}, J=17.1,10.2,7.0,7.0)$ & 4 \\
\hline 6 ' & $115.65, \mathrm{CH}_{2}$ & $\begin{array}{l}\text { a: } 5.03(\mathrm{ddt}, J=17.1,2.0,1.7,1.7) \\
\text { b: } 4.97(\mathrm{ddt}, J=10.2,2.0,1.7,1.7)\end{array}$ & $\begin{array}{l}4^{\prime}, 5 \\
4^{\prime}, 5\end{array}$ \\
\hline $7^{\prime}$ & $16.44, \mathrm{CH}_{3}$ & $1.30(\mathrm{~d}, 7.1)$ & $2,3,4$ \\
\hline
\end{tabular}

*: the numbers correspond to carbon atoms as shown in Fig. 2.

performed in triplicate. $\mathrm{The}^{\mathrm{IC}_{50}}$ values were calculated by non-linear regression using GraphPad Prism ${ }^{\circledR}$ Version 5.01 software. The selective index (SI) was calculated by dividing $\mathrm{IC}_{50}$ Vero cells/ $\mathrm{IC}_{50} L$. $(V$. $)$ braziliensis.

\section{RESULTS}

Fig. 1 summarises the chromatographic fractionation steps used to isolate compounds 1-7 from crude EtOAc extract of $N$. pseudotrichia. Among the seven isolated compounds, three (1-3) are reported here for the first time.
Compound 1 (Fig. 2) was isolated as a colourless oil. Its HRMS spectrum showed a $[\mathrm{M}+\mathrm{H}]^{+}$peak with $\mathrm{m} / \mathrm{z}$ 341.1593, compatible with the molecular formula $\mathrm{C}_{17} \mathrm{H}_{24} \mathrm{O}_{7}$. The ${ }^{1} \mathrm{H}$ - and ${ }^{13} \mathrm{C}-\mathrm{NMR}$ data (Table I) of one were very similar to those of trichoderonic acid $\mathrm{A}$ and (+)-heptelidic acid (Yamaguchi et al. 2010). However, one displayed signals $\delta_{\mathrm{H}} 2.02$ and $\delta_{\mathrm{C}} 172.00$ that were attributed to an acetyl group, which on the basis of HMBC correlations between $\mathrm{H}-10$ and $\mathrm{C}-15$, was allocated to $\mathrm{C}-10$. The large coupling constants between $\mathrm{H}-1$ and 


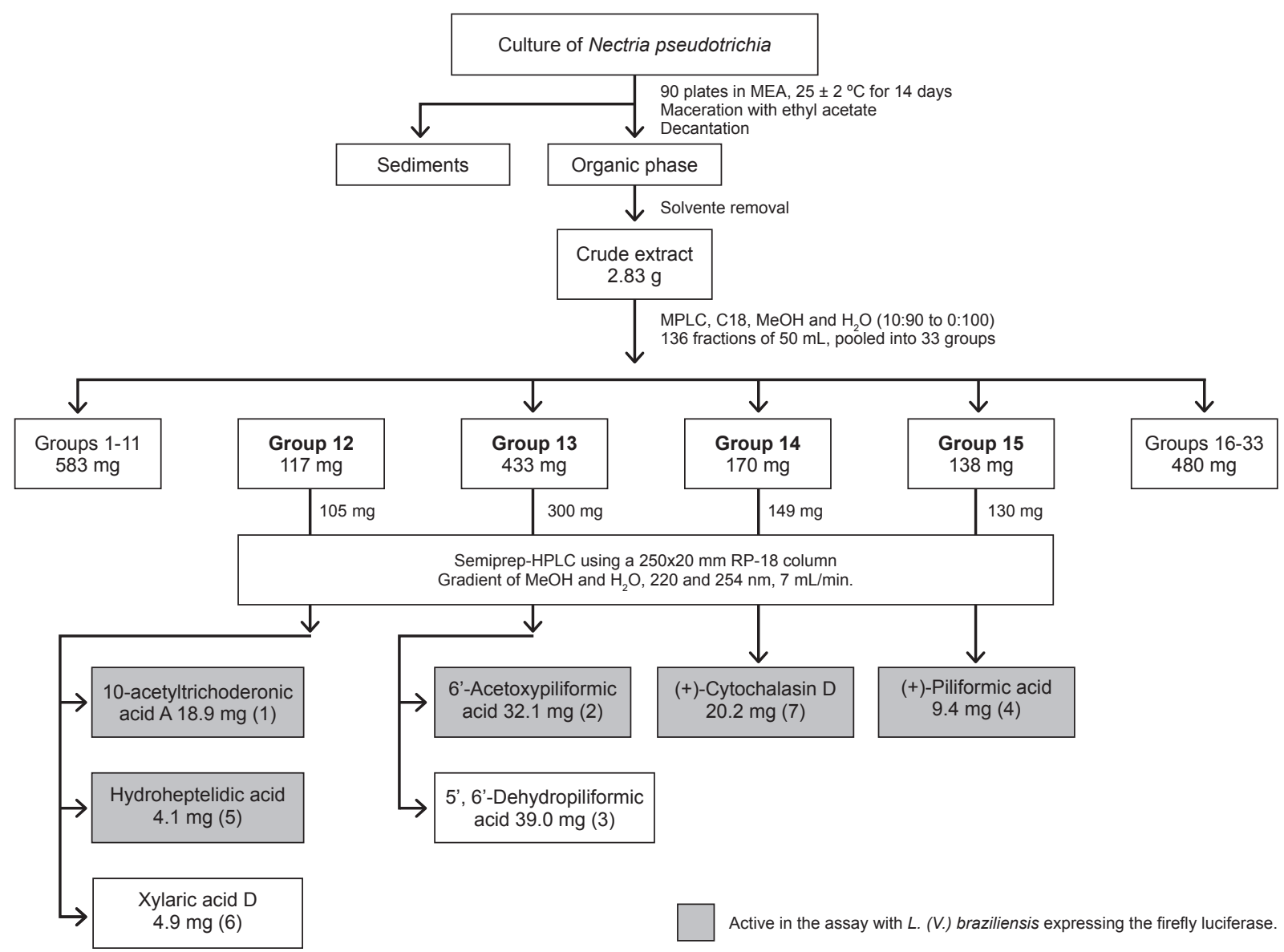

Fig. 1: fractionation steps indicating the procedures, yields, and the active compounds in the assay with amastigote forms of Leishmania (Viannia) braziliensis.

H-6, and H-6, and H-7 suggest an anti-orientation between them, indicating that the relative configurations at these positions are the same as in trichoderonic acid A (Yamaguchi et al. 2010). The NOESY experiment showed correlations between H-6 and H-11, H-12, H-13, and $\mathrm{H}-14$. It also showed correlations between $\mathrm{H}-1$ and $\mathrm{H}-7$, corroborating the relative configuration shown in Fig. 2 (Yan et al. 2011). Furthermore, as both compound 1 and trichoderonic acid A have dextrorotatory activities, we propose that their absolute configuration is the same. Thus, one was identified as $(+)-(5 \mathrm{a} S, 6 R, 9 S, 9 \mathrm{a} S)-9-$ (acetyloxy)-9-(hydroxymethyl)-1-oxo-6-(propan-2-yl)1,3,5a,6,7,8,9,9a-octahydro-2-benzoxepine-4-carboxylic acid, namely 10 -acetyltrichoderonic acid.

Compound 2 (Fig. 2) was isolated as a pale yellow gum. Its molecular formula was determined by ESIHRMS to be $\mathrm{C}_{13} \mathrm{H}_{19} \mathrm{O}_{6}$. The compound showed ${ }^{1} \mathrm{H}$ - and ${ }^{13} \mathrm{C}-\mathrm{NMR}$ data (Table II) similar to those of (+)-piliformic acid (4) (Anderson et al. 1985), with the major differences being the signals due the presence of an acetoxy moiety $\left(\delta_{\mathrm{H}} 2.02 \mathrm{~s}, \delta_{\mathrm{C}} 20.97\right.$ and $\left.\delta_{\mathrm{C}} 173.23\right)$ which, on the basis of HMBC cross peaks between H- 6 ' $\left(\delta_{\mathrm{H}} 4.06\right)$ with the carbonyl of the acetoxy group $\left(\delta_{C} 173.23\right)$, led us to position this group at end of the aliphatic chain. The $(E)$-configuration was supported by NOESY cor- relations between $\mathrm{H}-3\left(\delta_{\mathrm{H}} 3.63\right)$ and $\mathrm{H}-2^{\prime}\left(\delta_{\mathrm{H}} 2.23\right.$ and $\left.\delta_{\mathrm{H}} 2.28\right)$. Compound 2 showed dextrorotatory activity $\left([\alpha]_{\mathrm{D}}^{25}+30.0\right)$ as did the synthetic compound $2(S)$-methyl-pent $(E)-3$-(methoxycarbonyl)-3-enoic acid $\left([\alpha]_{\mathrm{D}}^{25}+\right.$ 109) synthesised by Takashi et al. (1973) and for which the absolute configuration was established unambiguously. Thus, the absolute configuration of two was established (Fig. 2) and the compound identified as $(+)-6$ '-acetoxy-piliformic acid.

Compound 3 (Fig. 2) was isolated as a white powder, and its molecular formula was determined to be $\mathrm{C}_{11} \mathrm{H}_{16} \mathrm{O}_{4}$ by HRMS. As for compound 2, its ${ }^{1} \mathrm{H}$ and ${ }^{13} \mathrm{C}$ NMR spectra (Table III) were similar to those of (+)-piliformic acid (4) (Table IV), however it showed one extra degree of unsaturation. Indeed, ${ }^{1} \mathrm{H}$ and ${ }^{13} \mathrm{C}$ NMR showed signals confirming the presence of an extra double bond (Table III) in the structure. This double bond was positioned at the end of the aliphatic chain on the basis of the observed COSY correlations between protons H-5' with H-6' and $\mathrm{H}-4$ ', and the HMBC correlations between proton $\mathrm{H}-4$ ' with carbons C-5' and C-6'. The NOESY correlation between $\mathrm{H}-3$ and H-2', and the dextrorotatory activity of three indicates that it has the same absolute configuration as (+)-piliformic acid (4) (Table IV). Based on this evidence, the chemical structure of three is proposed to 
<smiles>[Z]C(C)[C@H]1CC[C@](CO)(OC(C)=O)[C@H]2C(=O)OCC(C(=O)O)=C[C@H]21</smiles>

1<smiles>[R]CCCC=C(C(=O)O)[C@H](I)C(=O)O</smiles>

2: $\mathrm{R}=-\mathrm{CH}_{2} \mathrm{CH}_{2} \mathrm{OC}(\mathrm{O}) \mathrm{CH}_{3}$ 3: $\mathrm{R}=-\mathrm{CH}=\mathrm{CH}_{2}$

4: $\mathrm{R}=-\mathrm{CH}_{2} \mathrm{CH}_{3}$

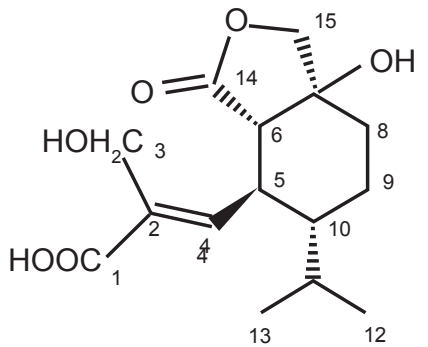

5

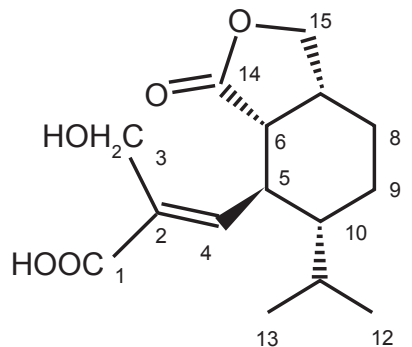

6

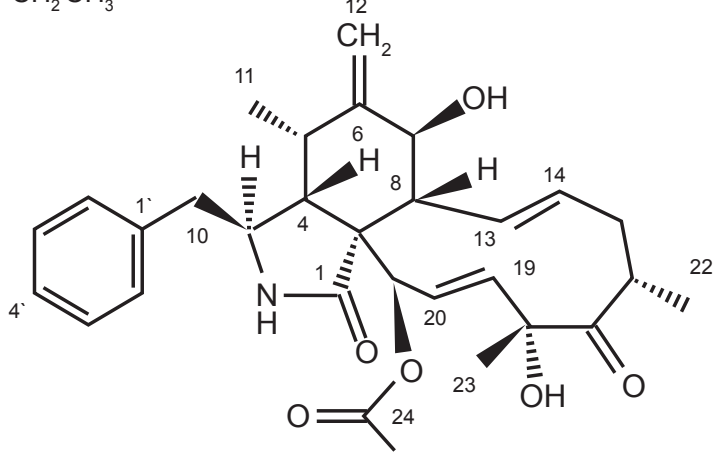

7

Fig. 2: structures of compounds 1-7 isolated from the endophytic fungus Nectria pseudotrichia.

be $(+)-(2 E, 3 S)-2-($ hept-6-en-1-ylidene)-3-methylsuccinic acid, and named 5',6'-dehydro piliformic acid.

Analytical and spectral data of compounds 4-7 (Fig. 2) were identical to those published in the literature for (+)-piliformic acid (4) (Anderson et al. 1985), hydroheptelidic acid (5) (Calhoun et al. 1992, Yan et al. 2011), xylaric acid D (6) (Yan et al. 2011), and (+)-cytochalasin D (7) (Cafeu et al. 2005).

All compounds were tested against amastigotes forms of L. (V.) braziliensis (Table V; Supplementary data, Fig. 1 ) and compounds 1,2 , and 5 were more active, with $\mathrm{IC}_{50}$ values of $21.4,28.3$, and $24.8 \mu \mathrm{M}$, respectively. Compounds 4 and 7 showed $\mathrm{IC}_{50}$ values of 78.5 and $72.6 \mu \mathrm{M}$, respectively. None of these compounds were cytotoxic to THP-1 and Vero cells in the concentration range tested (Table V; Supplementary data, Figs 2-3). The $\mathrm{IC}_{50}$ values for amphotericin B on Vero and THP-1 cells were 18.2 and $12.0 \mu \mathrm{M}$, respectively. Considering that the $\mathrm{IC}_{50}$ values for all compounds were greater than $200 \mu \mathrm{M}$ towards Vero and THP-1 cells (Table V), the selectivity indexes ranged from 2.5 (compound 4) to 9.3 (compound 1).

\section{DISCUSSION}

In our previous study, the crude extract from the culture of $N$. pseudotrichia disclosed antileishmanial activity without apparent toxicity to human peripheral blood mononuclear cells (Campos et al. 2015). These results prompted us to pursue the isolation and identification of the active metabolites in the extract (Figs 1-2). Thus, three compounds were considered active when tested on intracellular amastigote forms of $L$. (V.) braziliensis: 6'-acetoxy-piliformic acid (2), piliformic acid (4), and hydroheptelidic acid (5).
The $\mathrm{IC}_{50}$ values of isolated compounds 1,2 , and 5 in our study were $\sim 10$ times lower than the $\mathrm{IC}_{50}$ values determined for meglumine antimoniate $(178.2-330.2 \mu \mathrm{M})$ and paromomycin (233.6-344.4 $\mu \mathrm{M})$, but $\sim 5$ times higher than the $\mathrm{IC}_{50}$ values determined for miltefosine $(0.8$ $5.4 \mu \mathrm{M})$ and azithromycin $(5.7 \mu \mathrm{M})$, and $\sim 1000$ times higher than the $\mathrm{IC}_{50}$ values obtained for amphotericin $\mathrm{B}$ (0.02-0.06 $\mu \mathrm{M})$ in the assay with amastigote forms of L. (V.) braziliensis strain MHOM/BR/75/M2903 using different time periods of drug exposure (three, five, and seven days) (de Morais-Teixeira et al. 2014). Moreover, the $\mathrm{IC}_{50}$ value for amphotericin $\mathrm{B}(0.12 \mu \mathrm{M})$, used as positive control in our assays, was also $\sim 200$ times lower than the $\mathrm{IC}_{50}$ determined for compounds 2, 4, and 5 .

Considering compounds 1, 5, 6 (Fig. 2), and heptelidic acid (Fig. 3), we hypothesise that they originate from a putative common precursor that could cyclise in two different ways to form five and seven membered lactone rings (Fig. 3, routes $a$ and $b$, respectively). Compound 1 could be formed by opening of the epoxy ring of heptelidic acid by an acetoxy group (Fig. 3), while 2 and 3 are close variants of piliformic acid. According to Arigoni (1975), who investigated the biosynthesis of heptelidic acid, this compound was originally isolated from the ascomycete Anthostoma avocetta at Sandoz Pharmaceuticals (Sandoz AG) in 1971 and was named avocettin. The first total synthesis of heptelidic acid was achieved by the Danishefsky group in 1988 (Danishefsky \& Mantlo 1988). Recently, Rahier et al. (2015) reported the large-scale production of heptelidic acid and the semi synthesis of several derivatives for structure activity relationship (SAR) studies using more than 100 cancer cell lines and in vivo and pharmacokinetics 
TABLE IV

NMR Spectroscopic Data (400 MHz in $\mathrm{CD}_{3} \mathrm{OD}$ ) for compound 4

\begin{tabular}{|c|c|c|c|}
\hline \multirow[b]{2}{*}{ C position } & \multicolumn{3}{|c|}{ Compound 4} \\
\hline & $\delta_{\mathrm{C}}$ (mult.) & $\delta_{\mathrm{H}}($ mult., $J \mathrm{~Hz})$ & $\mathrm{HMBC}^{*}$ \\
\hline 1 & $170.08, \mathrm{C}$ & & \\
\hline 2 & $134.26, \mathrm{C}$ & & \\
\hline 3 & $38.81, \mathrm{CH}$ & $3.62(q, 7.1)$ & $1,2,4,1 ', 7^{\prime}$ \\
\hline 4 & $177.88, \mathrm{C}$ & & \\
\hline $1^{\prime}$ & $145.16, \mathrm{CH}$ & $6.83(\mathrm{t}, 7.7)$ & $1,2,3,1$ ', 2' \\
\hline $2^{\prime}$ & $29.48, \mathrm{CH}_{2}$ & $\begin{array}{l}\text { a: } 2.21 \text { (dddd, } 14.7,7.7,7.2,7.2) \\
\text { b: } 2.26(\text { dddd, } 14.7,7.7,7.2,7.2)\end{array}$ & 2,1 \\
\hline $3^{\prime}$ & $29.48, \mathrm{CH}_{2}$ & 1.49 (quin like, 7.2 ) & $1^{\prime}, 4^{\prime}, 5^{\prime}$ \\
\hline $4^{\prime}$ & $32.71, \mathrm{CH}_{2}$ & $1.36(\mathrm{~m})$ & \\
\hline 5 & 23.57, $\mathrm{CH}_{2}$ & $1.33(\mathrm{~m})$ & \\
\hline $6^{\prime}$ & $14.36, \mathrm{CH}_{3}$ & $0.92(\mathrm{t}, 7.0)$ & $4^{\prime}, 5^{\prime}$ \\
\hline $7^{\prime}$ & $16.37, \mathrm{CH}_{3}$ & $1.30(\mathrm{~d}, 7.1)$ & $2,3,4$ \\
\hline
\end{tabular}

*: the numbers correspond to carbon atoms as shown in Fig. 2.

TABLE V

Activity of the isolated compounds 1-7 on intracellular amastigote forms of Leishmania (Viannia) braziliensis, Vero and THP-1 cell lines

\begin{tabular}{lccc}
\hline Sample & L. $\left(\right.$ V.) braziliensis $\mathrm{IC}_{50}(\mu \mathrm{M})$ & $\mathrm{THP}^{-1} \mathrm{IC}_{50}(\mu \mathrm{M})$ & $\mathrm{Vero} \mathrm{IC}_{50}(\mu \mathrm{M})$ \\
\hline 1 & 21.4 & $>200$ & $>200$ \\
2 & 28.3 & $>200$ & $>200$ \\
3 & $>200$ & $>200$ & $>200$ \\
4 & 78.5 & $>200$ & $>200$ \\
5 & 24.8 & $>200$ & $>200$ \\
6 & $>200$ & $>200$ & $>200$ \\
7 & 72.6 & $>200$ & $>200$ \\
Amphotericin B & 0.12 & 12.0 & 18.2 \\
\hline
\end{tabular}

analysis in tumour xenographs. They concluded that heptelidic acid is a non-selective cytotoxic agent $\left(\mathrm{IC}_{50}\right.$ values between 0.4 and $3 \mu \mathrm{M}$ ) that displays very modest activity in vivo and, as a consequence, is not a viable option for human cancer therapy. They also concluded, based on the SAR results, that both the epoxide and the seven-member lactone rings are essential for bioactivity. In our experiments, the novel natural product (1), in which the epoxide ring of heptelidic acid was opened, was active in the assays with $L$. (V.) braziliensis. Hydroheptelidic acid (5), in which the epoxide was absent and the 7-membered lactone ring was substituted by a 5-membered lactone, showed activity against amastigote forms of $L$. (V.) braziliensis. Interestingly, if compound 5 eliminated a water molecule to form compound 6 , the activity against $L$. (V.) braziliensis was lost (Table V).

Piliformic acid (4) was previously isolated from $\mathrm{Hy}$ poxylon deustum (Anderson et al. 1985) and reported to be toxic to KB cells (derived from human mouth epidermoid carcinoma) and BC-1 human breast cancer cells with $\mathrm{IC}_{50}$ values of $13 \mu \mathrm{g} / \mathrm{mL}$ and $5 \mu \mathrm{g} / \mathrm{mL}$, respectively. In addition, piliformic acid isolated from Xylaria sp. strain CY-6884 was considered inactive at $25 \mathrm{nM}$ when tested against Plasmodium falciparum (3D7) and A549 cells (adenocarcinomic human alveolar epithelial cells) (Calcul et al. 2013).

In the current investigation, two new derivatives of piliformic acid with different moieties at the end of the alkyl side chain, 6'-acetoxypiliformic acid and 5',6'-dehydropiliformic acid, were isolated. Among them, 6'-acetoxypiliformic acid (2) demonstrated better antileishmanial activity when compared to piliformic acid (4), while 5',6'-dehydropiliformic acid was not active (Table V). Based on the results with $L$. (V.) braziliensis LUC, we suggest that the moiety at the end of the alkyl side chain influences the antileishmanial activity.

Although cytochalasin D (7) showed high $\mathrm{IC}_{50}$ value against $L$. ( $V$.) braziliensis in our assays, Roy et al. (2014) showed that this compound is able to destabilise the actin cytoskeleton of macrophages and reduce the 

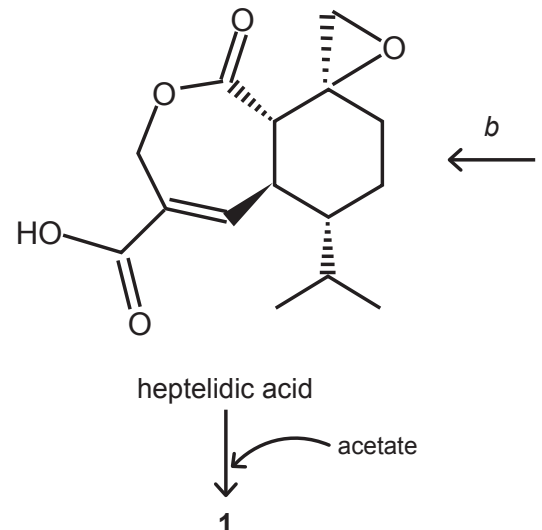

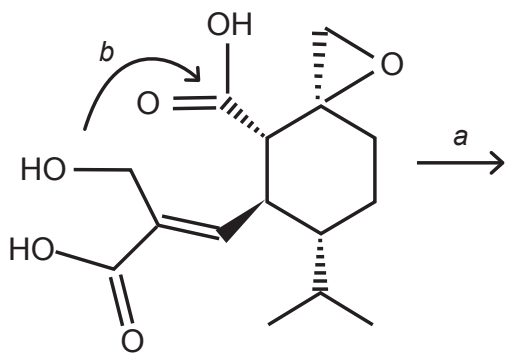

hypothetical precursor
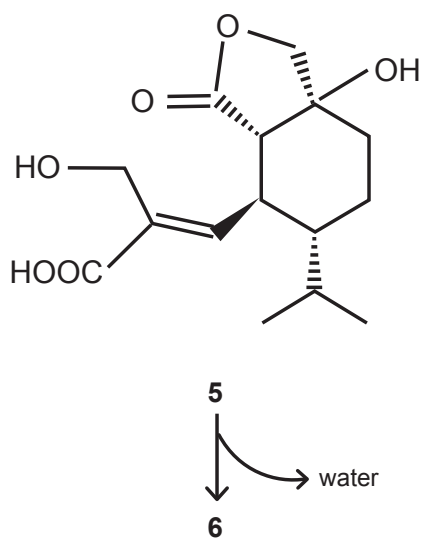

Fig. 3: hypothetical biosynthetic precursor to explain the formation of compounds $1,5,6$, and heptelidic acid.

attachment of Leishmania promastigotes and the intracellular amastigote load. These results reveal that the host actin cytoskeleton is responsible for parasite entry and infection. Another compound from the same class, 18-des-hydroxy cytochalasin $\mathrm{H}$, isolated from the ethyl acetate extract from the endophytic fungus Diaporthe phaseolorum-92C, reduces the viability of L. amazonensis promastigotes $\left(\mathrm{IC}_{50}\right.$ of $9.2 \mu \mathrm{g} / \mathrm{mL}$ ) (Brissow et al. 2017). Cytochalasins induce inhibition of cellular motility by affecting the rate of actin polymerisation; this is a promising strategy for the discovery of new drugs to treat leishmaniasis (Roy et al. 2014).

We evaluated the cytotoxic activity of isolated compounds (1-7) on Vero cells, a normal line of kidney fibroblasts from African green monkey. The cytotoxicity was also assessed on THP-1, a human leukaemia monocytic cell line that has been extensively used to study monocyte/macrophage functions (Chanput et al. 2014). Vero cells are generally more sensitive (Bueno et al. 2011) and are often used to assess toxicity in antitumor tests because they are not derived from tumours. Although the lack of aqueous solubility limited the use of higher concentrations of the isolated compounds in the assays with mammalian cells, our results demonstrate that all compounds were more selective to the parasite.

The Lipinski rules were established for oral administration of drugs based on the physicochemical profiles of phase II drugs indicating their solubility and permeability (Lipinski et al. 2001). The isolated compounds (1-7) satisfied some Lipinski simplified rules such as having a molecular weight (MW) $\leq 500$ or the logarithm of the octanol-water partition coefficient, $\log P(\mathrm{o} / \mathrm{w})$ is $<5$. The $\log P$ values of the isolated compounds were between -1 and 3 (Supplementary data, Table), similar to several drugs in clinical use (pentamidine, miltefosine, and amphotericin B) to treat leishmaniasis.

Most of the active compounds (1,2,4, and 5) have acid moieties in their structures with the possibility of interand intramolecular interactions through hydrogen bonds, which make these compounds slightly ionisable. However, less-ionisable compounds tend to permeate more easily in the membrane. Although natural products can violate some rules, the confirmatory test against intracellular amastigotes showed their potential as anti-parasitic drugs.
The Molinspiration Cheminformatics software was used to predict bioactivity of isolated compounds. Compounds 1,5 , and 6 had the best scores, suggesting their ability to act as enzyme inhibitors (Supplementary data, Table). The molecular docking analysis to test the isolated bioactive compounds toward target proteins from Leishmania spp. could help us to elucidate their mechanisms of action. However, there are more than 52 different protein structures of Leishmania spp. and new investigations are necessary to guide future experiments (Ogungbe et al. 2014).

In a search carried out in the SciFinder Scholar (searched on July 26, 2017), few studies have reported compounds isolated from fungal sources with antileishmanial activity. We highlight the compounds terrain, butyrolactone I, and butyrolactone $\mathrm{V}$, isolated from $A s$ pergillus terreus-F7, an endophytic fungus from Hyptis suaveolens (L.) Poit, which showed antileishmanial activity against $L$. amazonensis with $\mathrm{IC}_{50}$ values from 23.7 to $78.6 \mu \mathrm{M}$ and low cytotoxicity toward the normal cell line $\mathrm{GM} 07492 \mathrm{~A}\left(\mathrm{IC}_{50}\right.$ values from $3.4 \times 10^{3}$ to $15.3 \times 10^{3}$ $\mu \mathrm{M})$ (da Silva et al. 2017). Thus, the search for bioactive natural products is an alternative for seeking new scaffolds aimed at developing antileishmanial drugs.

In summary, this is the first report on the chemical investigation of N. pseudotrichia as a source of novel natural products with activity against intracellular amastigote forms of $L$. (V.) braziliensis and relative non-toxicity to mammalian cells.

\section{ACKNOWLEDGEMENTS}

To JO Rego, IR Andrade, ACO Nogueira, and MGC Fernandes from Fundação Zoo-Botânica de Belo Horizonte (FZB-BH), for providing the plant material. The authors are grateful to SRB Uliana for providing the Leishmania strain, and RL Monte Neto, for supporting the antileishmanial assay.

\section{AUTHORS' CONTRIBUTION}

FFC contributed in collecting and identifying the fungus. $\mathrm{BBC}$ contributed extraction, isolation, structures identification, and wrote the manuscript. LGT and DNB performed the antileishmanial and THP-1 assays. EMSF designed and JPR performed the cytotoxic assays with Vero cells. DMO contributed to structural elucidation and MK contributed to mass 
spectrometry experiments. CLZ and TMAA participated in the structural identification and writing of the manuscript.

\section{REFERENCES}

Anderson JR, Edwards RL, Whalley AJS. Metabolites of the higher fungi. Part 22. 2-Butyl-3-methylsuccinic acid and 2-hexylidene3 -methylsuccinic acid from xylariaceous fungi. J Chem Soc Perkin. 1985; 7(0): 1481-5.

Arigoni D. Stereochemical aspects of sesquiterpene biosynthesis. Pure Appl Chem. 1975; 41(1-2): 219-45.

Brissow ER, da Silva IP, de Siqueira KA, Senabio JA, Pimenta LP, Januário AH, et al. 18-Des-hydroxy cytochalasin: an antiparasitic compound of Diaporthe phaseolorum-92C, an endophytic fungus isolated from Combretum lanceolatum Pohl ex Eichler. Parasitol Res. 2017; 116(7): 1823-30.

Bueno J, Escobar P, Martínez JR, Leal SM, Stashenko EE. Composition of three essential oils, and their mammalian cell toxicity and antimycobacterial activity against drug resistant-tuberculosis and nontuberculous mycobacteria strains. Nat Prod Commun. 2011; 6(11): 1743-8.

Cafeu MC, Silva GH, Teles HL, Bolzani VDS, Araujo AR, Young MCM, et al. Antifungal compounds of Xylaria sp., an endophytic fungus isolated from Palicourea marcgravii (Rubiaceae). Quim Nova. 2005; 28(6): 991-5.

Calcul L, Waterman C, Ma WS, Lebar MD, Harter C, Mutka T, et al. Screening mangrove endophytic fungi for antimalarial natural products. Mar Drugs. 2013; 11(12): 5036-50.

Calhoun LA, Findlay JA, Miller JD, Whitney NJ. Metabolites toxic to spruce budworm from balsam fir needle endophytes. Mycol Res. 1992; 96(4): 281-6

Campos FF, Sales Jr PA, Romanha AJ, Araújo MSS, Siqueira EP, Resende JM, et al. Bioactive endophytic fungi isolated from Caesalpinia echinata Lam. (Brazilwood) and identification of beauvericin as a trypanocidal metabolite from Fusarium sp. Mem Inst Oswaldo Cruz. 2015; 110(1): 65-74.

Chanput W, Mes JJ, Wichers HJ. THP-1 cell line: an in vitro cell model for immune modulation approach. Int Immunopharmacol. 2014; 23(1): 37-45

da Silva IP, Brissow E, Kellner Filho LC, Senabio J, de Siqueira KA, Vandresen Filho S, et al. Bioactive compounds of Aspergillus terreus-F7, an endophytic fungus from Hyptis suaveolens (L.) Poit. World J Microbiol Biotechnol. 2017; 33(3): 62.

Danishefsky SJ, Mantlo N. Total synthesis of ( \pm )-heptelidic acid. J Am Chem Soc. 1988; 110(24): 8129-33.

de Morais-Teixeira E, Gallupo MK, Rodrigues LF, Romanha AJ, Rabello A. In vitro interaction between paromomycin sulphate and four drugs with leishmanicidal activity against three NewWorld Leishmania species. J Antimicrob Chemother. 2014; 69(1): 150-4.

Irvine NM, Yerkes CN, Graupner PR, Roberts RE, Hahn DR, Pearce $\mathrm{C}$, et al. Synthesis and characterisation of synthetic analogs of cinnacidin, a novel phytotoxin from Nectria sp. Pest Manag Sci. 2008; 64(9): 891-9.

Lipinski CA, Lombardo F, Dominy BW, Feeney PJ. Experimental and computational approaches to estimate solubility and permeability in drug discovery and development settings. Adv Drug Deliv Rev. 2001; 46(1-3): 3-26.
Monks A, Scudiero D, Skehan P, Shoemaker R, Paull K, Vistica D, et al. Feasibility of a high-flux anticancer drug screen using a diverse panel of cultured human tumor cell lines. J Natl Cancer Inst. 1991; 83(11): 757-66

Nassif PW, Castilho-Peres M, Rosa AP, Silva AL, Aristides SM, Lonardoni MV, et al. Clinical, laboratory, and therapeutic characteristics of American tegumentary leishmaniasis in the 15 th State Health Division, Northwest Paraná state, Southern Brazil. Rev Soc Bras Med Trop. 2016; 49(5): 593-601.

Ogungbe IV, Erwin WR, Setzer WN. Antileishmanial phytochemical phenolics: molecular docking to potential protein targets. J Mol Graph Model. 2014; 48: 105-17.

Parisot D, Devys M, Férézou JP, Barbier M. Pigments from Nectria haematococca: anhydrofusarubin lactone and nectriafurone. Phytochemistry. 1983; 22(5): 1301-3.

Pereira LO, Moreira RB, de Oliveira MP, Reis SO, de Oliveira Neto MP, Pirmez C. Is Leishmania (Viannia) braziliensis parasite load associated with disease pathogenesis? Int J Infect Dis. 2017; 57: 132-7.

Prates FV, Dourado ME, Silva SC, Schriefer A, Guimarães LH, Brito $\mathrm{MD}$, et al. Fluconazole in the treatment of cutaneous Leishmaniasis caused by Leishmania braziliensis: a randomized controlled trial. Clin Infect Dis. 2017; 64(1): 67-71.

Rahier NJ, Molinier N, Long C, Deshmukh SK, Kate AS, Ranadive $\mathrm{P}$, et al. Anticancer activity of koningic acid and semisynthetic derivatives. Bioorg Med Chem. 2015; 23(13): 3712-21.

Roy G, Dumas C, Sereno D, Wu Y, Singh AK, Tremblay MJ, et al. Episomal and stable expression of the luciferase reporter gene for quantifying Leishmania spp. infections in macrophages and in animal models. Mol Biochem Parasitol. 2000; 110(2): 195-206.

Roy S, Kumar GA, Jafurulla M, Mandal C, Chattopadhyay A. Integrity of the actin cytoskeleton of host macrophages is essential for Leishmania donovani infection. Biochim Biophys Acta. 2014; 1838(8): 2011-8.

Takashi M, Tetsuaki O, Kenji F. Pyrrolizidine alkaloids. The absolute configurations of latifolic acid and its stereoisomers. Chem Lett. 1973; 2(8): 773-6.

Tetko IV, Gasteiger J, Todeschini R, Mauri A, Livingstone D, Ertl P, et al. Virtual computational chemistry laboratory - design and description. J Comput Aided Mol Des. 2005; 19(6): 453-63.

Wang RS, Gong T, Zhu P, Cheng K. Isolation of metabolic products from the fungus Nectria sp. HLS206 that is associated with the marine sponge Gelliodes carnosa collected from the South China Sea. J Chin Pharm Sci. 2012; 21(2): 183-6.

WHO - World Health Organization. Control of leishmaniases. Technical Report Series 949. Report of a meeting of the WHO Expert Committee on the control of leishmaniases. Geneva: World Health Organization; 2010. 186 pp.

Yamaguchi Y, Manita D, Takeuchi T, Kuramochi K, Kuriyama I, Sugawara F, et al. Novel terpenoids, trichoderonic acids a and $\mathrm{b}$ isolated from Trichoderma virens, are selective inhibitors of family X DNA polymerases. Biosci Biotechnol Biochem. 2010; 74(4): 793-801.

Yan S, Li S, Wu W, Zhao F, Bao L, Ding R, et al. Terpenoid and phenolic metabolites from the fungus Xylaria $\mathrm{sp}$. associated with termite nests. Chem Biodivers. 2011; 8(9): 1689-1700. 